\title{
The Effect of Xylitol on Bone Alkaline Phosphatase Serum Level and Bone
} Defect Diameter in Rabbits

\author{
Ahmed H. Naji ${ }^{1 *}$, Wael T. Al-Watter ${ }^{2}$ and Ghada A. Taqa ${ }^{3}$ \\ ${ }^{1}$ Ministry of Health, Nineveh Health Directorate, Diyala, Iraq. \\ ${ }^{2}$ Department of Oral and Maxillofacial Surgery, College of Dentistry, University of Mosul, Mosul, Iraq. \\ ${ }^{3}$ Department of Dental Basic Sciences, College of Dentistry. University of Mosul , Mosul , Iraq. \\ *Corresponding Author: Ahmed H. Naji, E-Mail: ahmed.hatif.1990@gmail.com
}

\begin{abstract}
Our study aimed to investigate the systemic and topical effect of xylitol on the bone Alkaline Phosphatase and the bone mineral density in rabbits at the healing site in femur bone postoperatively. Twenty-four healthy white male, New Zealand rabbits, will be taken from the same species; the same age, Weight, and circumstance were chosen in this study. The Weight ranges from (1.3- 1.8) $\mathrm{Kg}$ and aged (6-8) months were used in this study ). All animals were submitted to operation in the femur bone region. The groove of $2 \mathrm{~mm}$ diameter was drilled in the femur bone by using the heavy-duty dental engine. After the operation, the rabbits were randomly divided into three groups ( 8 rabbits/group); each group was subdivided into 2 experimental periods (14,28 days) four rabbits for each period as follows: Control group, $\mathrm{n}=8$ (the hole was not filled by anything), locally treated group $\mathrm{n}=8$ (xylitol powder was applied and condensed well in the hole) and systemically treated group $n=8$ (the hole was not filled by anything but the rabbits received orally of $1 \mathrm{mg} / \mathrm{kg}$ of xylitol. Bone alkaline phosphates and radiological analysis were measured after 14 and 28 days, respectively. Statistical analysis showed significant differences between all groups (control and treated). Biochemical analysis for bone alkaline phosphatase showed a significant increase in bone Alkaline Phosphatase in the systemically treated group compared with the control one. The estimated bone healing by measuring the diameter of bone defect showed a highly significant difference in diameter in the bone defect at day 14 between the control group (36.0 \pm 0.05$)$ in comparison with the

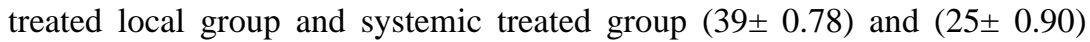
respectively. Also, we found a significant difference between the local treated group $(39 \pm 0.78)$ and systemic treated group $(25 \pm 0.90)$ in diameter. Still, on day 28 , there was no significant difference between the control group $(28.0 \pm 0.55)$ and the local treated group in diameter in the bone defects. There were significant differences between the control and the local treated groups compared with the systemic treated group $(24.0 \pm 0.23)$ at $\mathrm{p} \leq 0.05$. This study concluded that xylitol was accelerating bone healing when used topically and systemically, and this was indicated by increasing the bone alkaline phosphates and bone mineral density in densitometric analysis.
\end{abstract}

Keywords: Bone alkaline phosphatase, Bone density, Bone healing, xylitol.

\section{INTRODUCTION}

The bone structure is a hard organ that forms the part of the vertebrates' skeleton. Bones support and protect the body's various organs, produce white and red blood cells, provide structure, support the body, store minerals and allow mobility. Bones are present in a variety of sizes and shapes, with internal and external complicated structures. The bones are small and light, but they are formidable and difficult to defeat. (Gurgis
Original Article:

DOI:https://dx.doi.org/10.21608/javs.2 21.97815.1105

Received :24 September, 2021. Accepted:13 November, 2021. Published in January, 2022.

This is an open access article under the term of the Creative Commons Attribution 4.0 (CC-BY) International License. To view a copy of this license, visit:

http://creativecommons.org/licenses/by/4.0/

J. Appl. Vet. Sci., 7 (1): 6 - 10. et al., 2019) Bone tissue is a mineralized tissue consisting of cortical and cancellous bone. (Raina, $\boldsymbol{e t}$ al., 2019).

Xylitol is a sugar alcohol or polyalcohol, which is a polyol type of pentitol. It is easy to soluble in aqueous solutions, and that is related to it is composition. The xylitol is a five hydroxyl group sugar, making it a great affinity for water (Arcaño et 
al., 2020). Xylitol is the sweetest polyol, similar in sweetness to sucrose, but with a lower glycemic index and fewer calories (Awuchi and Echeta 2019). In addition to these advantages, xylitol has two main absorption pathways (intestinal flora and liver) that do not depend on insulin. The liver cell's permeability and their huge number of enzymes rapidly metabolize xylitol and turn it into energy.

However, the intestinal absorption of xylitol is quite slow. (Arcaño, et al., 2020). A biomarker is a characteristic that may be objectively tested and analyzed to detect normal biological processes, pathogenic processes, or pharmacological effects to a therapeutic intervention (Colloca, et al., 2020). Bone resorption and formation occur in structured cellular units called basic multicellular units during bone remodeling; hence, levels of bone turnover indicators reveal formation and resorption within basic multicellular units and the number of BMUs.(Ramchand and Seeman 2020). Alkaline phosphatases are found in a wide range of nature, from bacteria to humans. (Katsipis, et al., 2020).

Alkaline phosphatase determinations were applied to the bone diseases investigation by demonstrating the association between an increased alkaline phosphatase activity in serum and increased osteoblastic activity in bone; this association still forms the basis of the translation of serum alkaline phosphatase activities in bone diseases. Alkaline phosphatase (ALP) is a plasma membrane-bound glycoprotein that catalyzes phosphate monoesters' hydrolysis to release inorganic phosphate. These enzymes are mostly found in everybody's tissue (Sharma, et al., 2014). BALP is a significant marker of bone formation generated by osteoblasts and is positively related to the pace of bone production. (Gooding et al., 2019, Hussein and Taqa, 2021).

The study aimed to investigate the effect of topical and systemic applied of xylitol in Rabbits' femour on bone healing and to study the xylitol effect on bone mineral density and bone alkaline phosphatase.

\section{MATERIALS AND METHODS}

Twenty-four rabbits white New Zealand healthy male adult rabbits weighing from (1.5- 1.75) $\mathrm{Kg}$ and aged (7-8) months were used in our study. The animals were kept on standard condition and in the same circumstance of housing and feeding, given water from the same source and standard diet (wheat and fresh vegetables). The rabbits were housed in the rabbit cages in the animal house of the college of dentistry, University of Mosul under a veterinarian to check the animal's condition and general health before surgical procedure. The material used in this study xylitol is manufactured by the World Organic Company, Canada.

Animals were divided into 3 groups; each group consisted of 8 rabbits. All rabbits were Intramuscullary injected with a mixture of general anesthesia Ketamine hydrochloride $(40 \mathrm{mg} / \mathrm{kg}$ ) and xylazine $(5 \mathrm{mg} / \mathrm{kg})$ as a sedative, analgesic with muscle relaxant drug. Complete anesthesia had been achieved within 5 minutes. The rabbit was positioned in dorsal recumbency, preoperative aseptic precautions were achieved, and a manual hair clipper was used to remove the hair over the femur in the surgical place. The shaved area was washed with povidone-iodine as an antiseptic. Using surgical blade no.15, an incision about $1.5 \mathrm{~cm}$ was created over the femur bone near its head without any trauma to the muscle. The two muscles were separated to expose the femoral bone. The periosteum was elevated and exposed clear bone by blunt dissection using Hawarth periosteal elevator. Using round carbide bur $(2 \mathrm{~mm})$ attached to low speed straight surgical handpiece of a dental engine of (2000) rpm and vigorous irrigation with distilled water created small holes about $2 \mathrm{~mm}$ of both diameter and depth. The cavity was dried and cleaned with gauze.

The holes of partial bone defect in the first group were filled with xylitol using a spoon excavator. The second group cavity was filled with no material, the third group cavity was filled with no material, but the rabbits received $1 \mathrm{mg} / \mathrm{kg}$ of xylitol (C5H12O5)orally. The wound edges were approximated and closed via a $3 / 0$ black silk suture using a simple interrupted suturing technique and rubbing the area with povidone-iodine. Give Oxytetracycline(C22H24N2O9) $0.5 \mathrm{ml} / \mathrm{kg}$ was given immediately after surgical procedure one time daily for two days.

\section{Postoperatively:}

The operated rabbits were immediately isolated after the surgical procedure until they completely regained consciousness. They were monitored closely, especially during the first twenty hours after the surgical procedure, including feeding and physical activity. Four rabbits of each group were sacrificed after 14 days and the rest four after 28 days were sacrificed after $14^{\text {th }}$ and $28^{\text {th }}$ days after the operation. During animal sacrificing, blood samples were collected from the jugular vein, taken $5 \mathrm{ml}$ of blood, placed into plain tubes, and stored at room temperature for 30 minutes. The blood was centrifuged at $3000 \mathrm{rpm}$ for 20 minutes to separate the serum from whole blood. Serum was transferred by micropipette to Eppendorf tube and stored in a deep freeze at $-2^{0} \mathrm{C}$ to be thawed for analysis by using a microplate ELISA reader for 
rabbits bone alkaline phosphates kit and radiological analysis (bone mineral density (BMD) using Orthopantomograph Device)were measured after 14 and 28 days respectively.

\section{Statistical analysis:}

The data were expressed as mean \pm S.D., and there was a difference between groups and then statistically analyzed by one-way analysis of variance ANOVA followed by the post hoc Duncan's test. The level of significance was at $\mathrm{p} \leq 0.05$.

\section{RESULTS}

Bone Alkaline Phosphatase BALP: On day14:

ANOVA analysis test showed a highly significant difference in BALP between the control group (43.16 \pm 0.76$)$ in comparison with the treated local group and systemic treated group $(86 \pm 1.0)$ and (111.67 \pm 1.52$)$ respectively. Also, we found a significant difference between the local treated group (86 \pm 1.0$)$ and systemic treated group $(111.67 \pm 1.52)$ in BALP at day 14 ( Fig.1).

\section{Bone Alkaline Phosphatase BALP At day 28}

There was a significant difference between the control group (133.33 \pm 3.51$)$ and the other treated group (172.66 \pm 3.05$)$ and the systemic treated group $(342.0 \pm 2.0)$. Also, there was a significant difference between the local treated group $(172.66 \pm 3.05)$ and the systemic treated group $(342.0 \pm 2.0)$ at $p \leq 0.05$. Fig.1).

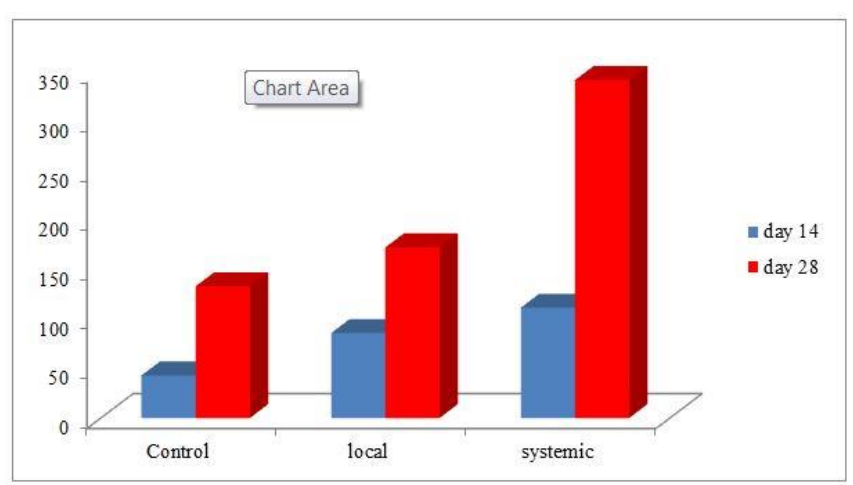

Fig.1: BALP concentration in rabbit's serum $(\mathrm{ng} / \mathrm{ml})$ between groups of the study on days 14 and 28 of treatment.

Evaluation Bone mineral density : (BMD) by measuring the diameter of the bony defect: At day14:

ANOVA analysis test showed a highly significant difference in diameter of the bony defect $(\mathrm{mm})$ between the control group $(36.0 \pm 0.05)$ in comparison with the treated local group and systemic treated group (39 \pm 0.78$)$ and $(25 \pm 0.90)$ respectively. Also, we found a significant difference between the local treated group $(39 \pm 0.78)$ and systemic treated group (25 \pm .90$)$ in diameter at day 14 (Fig.2and3).

\section{On day 28:}

There was no significant difference between the control group $(28.0 \pm 0.55)$ and the local treated group in defect bony diameter at day 28 . There were significant differences between the control and the local treated groups compared with the systemic treated group $(24.0 \pm 0.23)$ at $p \leq 0.05$. (Fig.2and3).

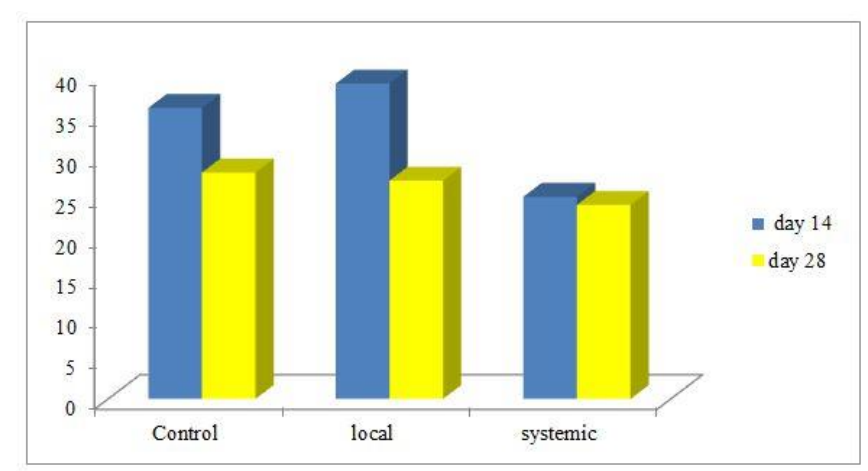

Fig.2: diameter of the bony defect $(\mathrm{mm})$ between groups of the study at days 14 and 28 of treatment.
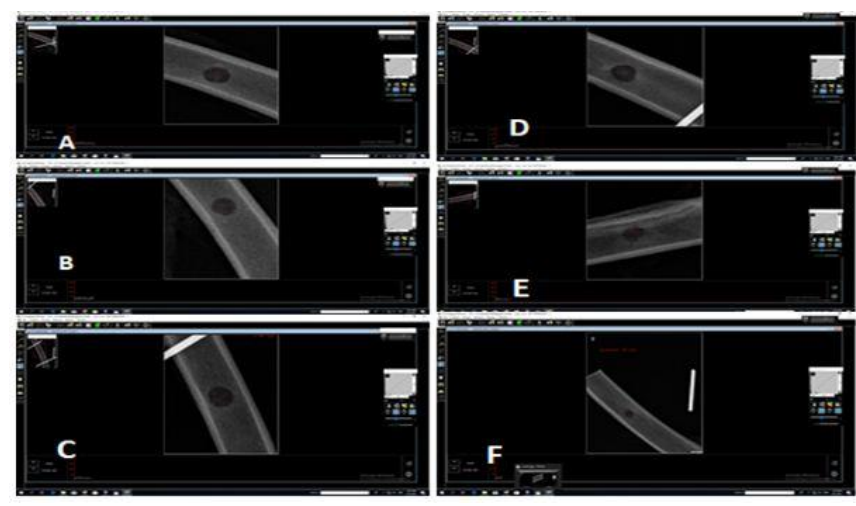

Fig.3: A: Densitometric analysis for control rabbit group at day 14; B. Densitometric analysis for local treated rabbit group at day 14. C. Densitometric analysis for local treated rabbit group at day 14. D; Densitometric analysis for control rabbit group at day 28; E; Densitometric analysis for local treated rabbit group at day 28. F; Densitometric analysis for systemic treated rabbit group at day 28 .

\section{DISCUSSION}

Xylitol is a potential natural sweetener in fruits and vegetables (Benahmed, et al., 2020). In this study, we found that the application of xylitol accelerated bone defect healing in rabbits when used locally and systemically. A bone defect in the absence of bone tissue in the same portion of the body as a result of injury, sickness, inflammation, congenital or traumatic causes. It can also happen as a result of continuing illnesses or surgical operations in some situations. When the bone loss regeneration process is slowed or even stopped, bone rebuilding through surgical implantation of materials is frequently required to enhance bone regeneration(Cheng, et al., 2011). In 
recent decades, materials used for bone repair have primarily been obtained from autograft materials due to their superior bone conduction, inducibility, and osteogenesis. In terms of bone healing, an autologous bone graft is still the treatment of choice in practical practice. (Chen, et al., 2010 ) However, the small amount of donor's bone and the complications involved with the harvesting process limit the clinical applicability of this approach. (Dashtban, et al., 2013).

As a result, various bone substitutes are important as alternate graft materials for successful bone reconstruction. The researcher tests serum BALP, which is one of the most commonly utilized bone biomarkers in clinical and preclinical studies and is a good translation tool. Bone alkaline phosphates are the bone-specific isoform of the enzyme serum alkaline phosphatase. It is a glycoprotein found on the surface of osteoblasts and reflects the activity of these cells in bone metabolism (Bonnick, et al., 2013). As such, Bone alkaline phosphates have generally been considered a reliable indicator of bone metabolism and the most important marker of osteoblast differentiation. In bone remodeling, if the resorption rate is greater than the rate of bone formation, bone loss leads to metabolic bone disease (osteoporosis, Paget disease) and fractures. Higher alkaline phosphatase levels may be attributed to increased chondroblastic proliferation during broken bone repair to induce bone formation (Yang et al., 2020).

The differences in bone healing across groups were substantial in the current study. The amount of Bone alkaline phosphates changed significantly. At 14 and 28 days, there was an increase in bone markers in both the control and treatment groups. These findings looked into whether there was a difference in bone growth between groups on day14 and the serum phosphorous mean values. The present study was in agreement with (Kumar et al., 2018) who found that serum alkaline phosphatase values increased significantly from preoperative day to $14^{\text {th }}$ day and decreased to normal levels by the 60th day after levels ( Kumar et al., 2018). In the present study, we found that xylitol increase bone healing and decrease the diameter of the bone defect; this effect may be returned to the role of xylitol that increases calcium and phosphorus level in bone, promotes the restoration of bone calcium ( Sato, et al., 2011, Arcaño, et al., 2018 ). Xylitol can bind with calcium ion leading to consequent remineralization of teeth enamel; it is also able to prevent osteoporosis (Benahmed, et al.,2020).

Also, xylitol suppresses the production of nitric oxide cytokines. Therefore, it has an anti-inflammatory effect and enhances bone healing (Ahuja, et al., 2020). Xylitol is a strong antioxidant with free radical scavenging activity and cell-protective effects, demonstrating membrane stabilizing activity against oxidative stress. Hence, A previous study found that when used antioxidant agent shown to function as an osteoclastogenesis inhibitor by down-regulating the development of reactive oxygen species (ROS) and has been indicated to have potential therapeutic implications for the treatment of osteoporosis and other bone diseases (Pal, et al., 2013).

\section{CONCLUSION}

Although bone may appear to be a rather static tissue, it is actually in continuous turnover. It is, therefore, important that there is a correct balance in the resorption and reconstruction of bone tissue. Dietary means to improve mineral absorption, bone mineral density, and bone strength are thus welcome, so we conclude that the natural sweeteners xylitol stimulate alkaline phosphates in the body and stimulate osteoclast and osteoblast in the bone defect in the body, and so accelerate bone defect healing.

\section{Declaration of Conflicting Interests}

The authors revealed that there is no potential conflicts of interest.

\section{REFERENCES}

AHUJA, V., MACHO, M., EWE, D., SINGH, M., SAHA, S., and SAURAV, K., 2020. Biological And Pharmacological Potential Of Xylitol: A Molecular Insight Of Unique Metabolism. Foods, 9(11), 1592. https://doi.org/10.3390/foods9111592.

ARCAÑ̃, Y. D., GARCÍA, O. D. V., MANDELLI, D. CARVALHO, W. A., and PONTES, L. A. M., 2020. Xylitol: A Review On The Progress And Challenges Of Its Production By Chemical Route. Catalysis Today, 344, 2-14. https://doi.org/10.1016/j.cattod.2018.07.060

AWUCHI, C. G., and ECHETA, K. C., 2019. Current Developments In Sugar Alcohols: Chemistry, Nutrition, And Health Concerns Of Sorbitol, Xylitol, Glycerol, Arabitol, Inositol, Maltitol, And Lactitol. International Journal of AdvancedAcademicResearch, 5,1-33. https://www.academia.edu/40798451

BENAHMED, A. G., GASMI, A., ARSHAD, M., SHANAIDA, M., LYSIUK, R., PEANA, M., and BJØRKLUND, G., 2020. Health Benefits Of Xylitol. Applied Microbiology and Biotechnology, 113., https://doi.org/10.1007/s00253-020-10708-7.

BONNICK, S., DE VILLIERS, T., ODIO, A., PALACIOS, S., CHAPURLAT, R., DASILVA, C., and GURNER, D., 2013. Effects Of Odanacatib On Bmd And Safety In The Treatment Of Osteoporosis In Postmenopausal Women Previously Treated With Alendronate: A Randomized Placebo-Controlled Trial. The Journal of Clinical Endocrinology and Metabolism, 98(12), 4727-4735. https://doi.org/10.1210/jc.2013-2020.

CHEN, X., JIANG, Z. H., CHEN, S., and QIN, W., 2010. Microbial And Bioconversion Production Of D-Xylitol 
And Its Detection And Application. Int. J. Biol. Sci. 6, 834-844. doi:10.7150/ijbs.6.834.

https://www.ijbs.com/v06p0834.htm.

CHENG, H., WANG, B., LV, J., JIANG, M., LIN, S., and DENG, Z., 2011. Xylitol Production From Xylose Mother Liquor: A Novel Strategy That Combines The Use Of Recombinant Bacillus Subtilis And Candida Maltose. Microbial Cell Factories, 10(1), 1-12. https://doi.org/10.1186/1475-2859-10-5.

COLLOCA, G., DI CAPUA, B., BELLIENI, A., FUSCO, D., CICIARELLO，F., TAGLIAFERRI， L., and BALDUCCI, L., 2020. Biological And Functional Biomarkers Of Aging: Definition, Characteristics, And How They Can Impact Everyday Cancer Treatment. Current Oncology Reports, 22(11), 1-12. 11. https://doi.org/10.1007/s11912-020-00977-w.

DASHTBAN, M., KEPKA, G., SEIBOTH, B., and QIN, W. 2013., Xylitol Production by Genetically Engineered Trichoderma reesei Strains Using Barley Straw as Feedstock. Appl. Biochem. Biotechnol. 169, 554-569 https://doi.org/10.1007/s12010-012-0008-y.

GOODING, S., OLECHNOWICZ, S. W., MORRIS, E. V., ARMITAGE, A. E., AREZES, J., FROST, J., and EDWARDS, C. M., 2019. Transcriptomic Profiling Of The Myeloma Bone-Lining Niche Reveals Bmp Signalling Inhibition To Improve Bone Disease. Nature communications, 10(1), 1-15. https://doi.org/10.1038/s41467-019-12296-1

GURGIS, G., OLORI, J., DAZA, J., BRENNAN, I., HUTCHINSON, M., and BAUER, A., 2019. Poster Abstracts: 3d Geometric Morphometric Analysis Of Pygopodid Gecko Skull Morphology And Relationship To Habitat. Integrative and Comparative Biology, 59(Supplement_1).https://researchers.anu.edu. au/researchers/brennan-i

HUSSEIN, A. A., and TAQA, G. A., 2021. The Impact of Natural Calcium Carbonate and Ubiquinone on Bone Mineral Density in Rabbits. Journal of Applied Veterinary Sciences, 6(4), 15-22.

https://dx.doi.org/10.21608/javs.2021.87062.1091.

KATSIPIS, G., TSALOUXIDOU, V., HALEVAS, E., GEROMICHALOU， E., GEROMICHALOS，G., and PANTAZAKI, A. A., 2021. In Vitro And In Silico Evaluation Of The Inhibitory Effect Of A CurcuminBased Oxovanadium (iv) Complex On Alkaline Phosphatase Activity And Bacterial Biofilm Formation. Applied Microbiology and Biotechnology, 105(1), 147168. https://doi.org/10.1007/s00253-020-11004-0.

KUMAR, V. D. PRASAD, N. D. LAKSHMI, and RAJU, N. K. B., 2018. Evaluation Of Biochemical Parameters For Assessment Of Fracture Healing In Dogs. Pharm. Innova. J, vol. 7, no. 3, pp. 577-580. http://www.thepharmajournal.com/archives/2018/vol7i ssue3/PartI/7-3-37-421.pdf

PAL, S., CHOUDHARY, V., KUMAR, A., BISWAS, D., MONDAL, A. K., and SAHOO, D. K., 2013. Studies On Xylitol Production By Metabolic Pathway Engineered Debaryomyces hansenii. Bioresource technology, 147, 449-455.

https://doi.org/10.1016/j.biortech.2013.08.065.

RAINA, D. B., QAYOOM, I., LARSSON, D., ZHENG, M. H., KUMAR, A., ISAKSSON, H., and TÄGIL, M., 2019. Guided Tissue Engineering For Healing Of
Cancellous And Cortical Bone Using A Combination Of Biomaterial Based Scaffolding And Local Bone Active Molecule Delivery. Biomaterials, 188, 38-49. https://doi.org/10.1016/j.biomaterials.2018.10.004.

RAMCHAND, S. K., and SEEMAN, E., 2020. Reduced Bone Modeling and Unbalanced Bone Remodeling: Targets for Antiresorptive and Anabolic Therapy. Bone Regulators and Osteoporosis Therapy, 423-450 -2. https://doi.org/10.1007/164_2020_354.

SATO, H., IDE, Y., NASU, M., and NUMABE, Y., 2011. The Effects Of Oral Xylitol Administration On Bone Density In Rat Femur. Odontology 99, 28-33. https://doi.org/10.1007/s10266-010-0143-2

SHARMA, U., PAL, D., and PRASAD, R., 2014. Alkaline Phosphatase: An Overview. Indian Journal of Clinical Biochemistry, 29(3), 269-278. https://doi.org/10.1007/164_2020 354.

YANG, B.-X., XIE, C.-Y., XIA, Z.-Y., W.U., Y. J., LI, B., and TANG, Y.Q., 2020. The Effect Of Xylose Reductase Genes On Xylitol Production By Industrial Saccharomyces Cerevisiae In Fermentation Of Glucose And Xylose. Process Biochem. 95, 122-130. https://doi.org/10.1016/j.procbio.2020.05.023.

ZHAO KANG, T., MOHAMMAD, S.H., ABD MURAD, A.M., ILLIAS, R., JAHIM, J.M., 2016. Fermentative Production of Xylitol: A First Trial on Xylose Bifurcation. Indian J. Sci. Technol. 9, 1-5. http://dx.doi.org/10.17485/ijst/2016/v9i21/95234.

\section{How to cite this article:}

Ahmed H. Naji, Wael T. Al-Watter and Ghada A. Taqa, 2022. The Effect of Xylitol on Bone Alkaline Phosphatase Serum level and Bone Defect Diameter in Rabbits . Journal of Applied Veterinary Sciences, 7 (1): $06-10$. DOI:https://dx.doi.org/10.21608/javs.2021.97815.1105 